\title{
A Comparison of Selected Measures of Physical Fitness in Women Subjects from Various Ethnic Groups and National Backgrounds
}

\author{
Donna Chun ${ }^{1}$, Norman Eburne ${ }^{1}$, Joseph Donnelly ${ }^{2}$, Norman Kaluhiokalani ${ }^{1}$, \\ Joke Kokkonen $^{1}$, and Jana Whitehead ${ }^{1}$ \\ ${ }^{1}$ Brigham Young University - Hawaii \\ ${ }^{2}$ Montclair State University
}

\begin{abstract}
This study compared fitness components in 317 women of different ethnicity from BYU-Hawaii. Data was analyzed using SPSS, ANOVA, t-tests, and Tukey's HSD Post-Hoc Test. Results showed American Caucasians were faster and leaner than Pacific Islanders and Hawaiians. American Caucasians, Pacific Islanders and Hawaiians were stronger than Asians. American Caucasians did more sit-ups than Pacific Islanders and Asians and more back extensions than Pacific Islanders. Asians were leaner than Pacific Islanders and Hawaiians, and faster than Pacific Islanders. Whether these differences resulted from genetics or socio-cultural factors is unclear. Differences may be remedied by ethnic norms as developed in this study.
\end{abstract}

(C) 2006 Californian Journal of Health Promotion. All rights reserved.

Keywords: Hawaii, API, Pacific Islanders, fitness

\section{Introduction}

The first Youth Fitness Test in the U. S. was developed in 1957 by the American Alliance for Health, Physical Education, Recreation, and Dance (American Alliance, 1957). Fitness standards were developed with no special accommodations made for specific populations or different ethnic groups. Today after nearly five decades of fitness testing, the population make-up of the U. S. has grown to include Caucasians, Black Americans, Hispanics, Native Americans, Asians and Pacific Islanders. Experts and practitioners are now taking a hard look at the current fitness standards and are beginning to question the need for ethnicspecific physical fitness standards.

Ethnic differences in percent body fat and body mass index have been well documented. Studies done by Deurenberg et al. (1998, 1999, 2000) show the relationship between percent body fat and body mass index is different among various ethnic groups due to differences in body build. For example, in the Chinese and Malays, the legs and arms are relatively shorter as compared to body height (Deurenberg-Yap et al., (2000).
In contrast Indians and Australian Aboriginals have longer legs (Norgan, 1995). Malays are more slender than Chinese and Indians. Slender subjects have less bone and muscle mass and less connective tissue, but have a higher percent body fat at the same body mass index than a person with a stocky build (Duerenberg et al. (1999). Thomas (1997b) found differences in total fat among ethnic groups with Native Americans having greater total fat than Caucasians. Thomas (1997a) also reported differences in regional fat between ethnic groups. African American, Caucasian and Mexican American women have more fat on the thigh. Native American women have more fat on the torso, less fat on the extremities, and reported the largest accumulation of fat in the abdomen. In addition Thomas (1997a) found African American women taller than Mexican Americans and Native Americans, and heavier than Mexican Americans and Caucasians. According to Wagner \& Heyward (2000), blacks have greater fat-free body density than whites, and have more fat on the trunk and back and less on the extremities and front of the body. 
Deurenberg-Yap et al (2000) studied the relationship between percent body fat and body mass index among Chinese, Malays, and Indians in Singapore in order to determine the validity of the body mass index cut-off points for obesity. It was found that the Singaporeans had a higher percent body fat at a lower body mass index than Caucasians. There were also differences among Chinese, Malays and Indians. For the same body mass index the Indians had the highest percent body fat and the Chinese the lowest. The body fat predicted from the body mass index using a Caucasian prediction equation was significantly underestimated in the three Singaporean groups. In a similar study by Wang et al. (1994) in New York it was found that Asians had a lower mean body mass index but a higher percent body fat than Caucasians. Gallagher et al (2000) found comparable results where Asians had significantly higher percent body fat at a given body mass index when compared to African Americans and whites. Likewise, Gurrici et al (1999) reported that Indonesians when compared to Caucasians, had a higher percent body fat at a lower body mass index, and noted that differences in skeletal and muscle mass could be partly responsible for the variation. Fernandez (2003) found that Hispanic women had more body fat than African and European American women at a BMI greater than

Wang et al (1994) noted that in addition to body build, the difference in the percent body fat and body mass index relationship could be due to physical activity; higher levels of physical activity increases muscle mass at the same body weight. There were fewer studies documenting the differences in aerobic capacity among ethnic groups. Pivarnik et al. (1995) found that aerobic capacity was lower among black girls as compared to white girls, and felt it was due to the smaller skeletal muscle tissue contained within the freefat mass. Bungum et al (1998) looked at the passing rates for the Fitnessgram in the one-mile run and body mass index in Asian and Pacific Islander (API) Youth. Similar results to the NCYFS (Looney \& Plowman, 1990) were found for the one-mile run for the boys, however, the passing rate for the API girls was $17 \%$ higher.
Due to the differences in body build among different ethnic groups, researchers are recommending the use of ethnic specific physical fitness standards. Thomas et al. (1997a, 1997b) found when comparing regional and total fat of African Americans, Caucasians, Mexican Americans and Native Americans that Caucasians were significantly different from the other groups and that use of Caucasian standards for minority groups may not be appropriate. Deurenberg et al. $(1999,2002)$ reported that the use of impedance formulas across ethnic groups without validation could result in biased information. Rush et al. (1997) found that at a fixed percent body fat, the Polynesian group had a higher BMI than the New Zealand European group. Rush concluded that the BMI standards used for whites should be revised for use with Polynesians. Because environmental and genetic factors are difficult to evaluate, Gallagher et al. (2000) do not recommend the use of a universal table of percent body fat without additional analysis. In a study comparing Cook Island Maoris and Caucasians from Australia, Swimburn et al (1999) concluded that specific standards for obesity for Polynesians need to be developed. In addition, Craig et al. (2001) concluded that the international standards for healthy weight ranges developed by the World Health Organization (1998) may not be acceptable for evaluation of Tongans.

\section{Purpose}

With Hawaii being an ethnically diverse state and with the multicultural background of students at BYU-Hawaii, this study was conducted to determine if there were any significant differences between ethnic groups in fitness components, and if it was possible to establish separate criteria for evaluative purposes.

\section{Hypotheses}

1) It is predicted that there will be no significant difference between pre and post test scores on any of the variables for women.

2) It is predicted that there will be no significant difference on the pre test scores 
among the ethnic groups on any of the variables for women.

\section{Method}

The college course EXS 177 Fitness for Life is a required General Education Course at Brigham Young University - Hawaii designed to teach students the basic principles of health and wellness and to help students incorporate a healthy lifestyle of proper physical activity, nutrition, and emotional and mental health. The data for this study was gathered over a period of ten years from Fall 1988 to Summer 1998. The classes were taught by faculty and part-time instructors in the department.

\section{Subjects and Ethnic Groups}

The subjects included 317 female students. The majority of subjects in the study were students of American Caucasian background. They represented $41 \%$ of all subjects. The Asian and Pacific Islander students each represented 22\%, the Hawaiian students $11 \%$, and the students of European Caucasian 3\%. In this study white students from the continental U.S. are referred to as American Caucasians as opposed to white students from the European continent. Forty-five percent of the subjects were from the mainland or continental U.S. Nineteen percent were from Hawaii, with $18 \%$ from the both the Pacific Islands and Asia. Only $1 \%$ was from the European continent.

\section{Fitness Tests}

The students were evaluated on the following fitness components: cardiovascular endurance (1.5 mile run), body composition (skinfold thickness analysis), flexibility (sit and reach), muscular strength (bench press and leg press), and muscular endurance (sit-up and back extension). Students were given a pre and post test. For the 1.5 mile run, students were timed for a distance of 1.5 miles. Calipers were used to measure the skinfold thickness on the right side of the body. The three sites used for the women included the triceps, iliac crest, and thigh. The flexibility box was used to measure the range of motion of the hamstrings and the lower back.
With the shoes removed, the heels of both feet were placed flat against the box while the knees remained straight. For the sit-up test, the hands were placed across the chest with the knees bent and feet flat on the floor held by a partner. The upper trunk was brought up and forward until the elbows touched the thighs, and then lowered until the upper back was in contact with the floor. Students were timed for 1 minute. The back extension was also a timed test for 1 minute with the students in the prone position, hands clasped behind the head and feet held by a partner. The upper body was raised to 45 degrees before lowering and touching the chest to the floor. Both the bench press and the leg press were administered in the BYU-Hawaii Fitness Center. The students were asked to lift the maximum weight possible once. For the leg press, the students were in the supine position with the knees at $90 \%$, and the feet placed flat on the platform and shoulder width apart. Depending on the experience of the students, the starting weight for the women was 50 pounds and the men at 100 pounds. The bench press was done on the weight machine with the grip starting even with the chest. The arms were then extended to lift the weight.

\section{Statistical Analysis}

The data was analyzed using SPSS (Statistical Package for Social Science). Frequency tables, descriptive statistics, t-tests, ANOVA, and Tukey's HSD Post-Hoc Test were conducted. For the t-tests, to correct for an increase in family-wise error rates, a Bonferroni adjustment was applied $(.05 / 7=.007)$. The null hypothesis was rejected when the t-value was less than .007. To correct for an increase in family-wise error rates for Tukey's HSD Post-Hoc Test, a Bonferroni adjustment was applied $(.05 / 7=$ .007). The null hypothesis was rejected when the F-value was less than .007.

\section{Results}

Table 1 shows paired t-test results comparing pre to post tests on all variables for the female students. The differences for all variables were significant. 
Table 1

Paired t-test for all fitness variables

\begin{tabular}{|l|r|r|l|l|c|c|}
\hline \multicolumn{1}{|c|}{ Test } & \multicolumn{1}{c|}{ Mean } & \multicolumn{1}{c|}{ SD } & N & R & t & p \\
\hline 1.5 Mile Pre Test & 952.02 & 188.25 & 317 & .842 & 14.40 & .000 \\
\hline 1.5 Mile Post Test & 869.02 & 166.22 & 317 & --- & --- & --- \\
\hline Skinfold Pre Test & 23.26 & 7.01 & 306 & .923 & 4.79 & .000 \\
\hline Skinfold Post Test & 22.53 & 6.65 & 306 & --- & --- & --- \\
\hline Sit/Reach Pre Test & 15.88 & 3.92 & 312 & .867 & -11.24 & .000 \\
\hline Sit/Reach Post Test & 17.13 & 3.57 & 312 & --- & --- & --- \\
\hline Sit-up Pre Test & 33.52 & 10.99 & 308 & .805 & -18.69 & .000 \\
\hline Sit-up Post Test & 40.91 & 11.22 & 308 & --- & --- & --- \\
\hline Back Ext Pre Test & 52.28 & 13.57 & 309 & .615 & -24.14 & .000 \\
\hline Back Ext Post Test & 68.29 & 13.00 & 309 & --- & --- & --- \\
\hline Bench Press Pre & 75.77 & 23.41 & 285 & .921 & -15.25 & .000 \\
\hline Bench Press Post & 84.72 & 25.48 & 285 & --- & --- & --- \\
\hline Leg Press Pre Test & 135.26 & 64.79 & 298 & .623 & -7.15 & .000 \\
\hline Leg Press Post Test & 157.14 & 55.10 & 298 & --- & --- & --- \\
\hline
\end{tabular}

\section{Analysis for Women Ethnic Groups}

Results of the analysis using ANOVA and Tukey's HSD Post-Hoc Test comparing ethnic groups on variables with significant differences are found in Appendix A (Tables 1-5. Significant differences were found for the 1.5 mile run, skinfold thickness, sit-ups, back extensions, and bench press. There were no significant differences found for the sit and reach and the leg press when compared by ethnic groups.

For the 1.5 Mile Run, there were significant differences between the Asian and Pacific Islander students, and also between the American Caucasian and both the Pacific Islander and Hawaiian students (see Appendix $\underline{\text { A }}$, Table 1). Significant differences were found for skinfold thickness for the Asian and American Caucasian students when compared to both the Pacific Islander and Hawaiian students (see Appendix A, Table 2). When comparing the sit-up test by ethnic groups, it was found that there were significant differences between American Caucasian and both the Asian and Pacific Islander students (see Appendix A, Table $3)$. Significant differences were found on the back extension test for the American Caucasian and the Pacific Islander students (see Appendix

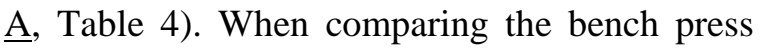
by ethnic groups, there were significant differences between the Asian students and all other ethnic groups except for the European students (see Appendix A, Table 5).

\section{Percentile Scores}

Norms by decile were computed for each ethnic group on all variables (see Appendix B).

\section{Conclusions}

Based upon the data in this study, the following null hypotheses were rejected: 1) For comparison of ethnic groups on all variables: a) The null hypothesis was rejected on female 1.5 mile run for Pacific Islanders vs. Asians, American Caucasians vs. both Pacific Islanders and Hawaiians; b) The null hypothesis was rejected on female skinfold thickness for Pacific Islanders vs. both Asians and American Caucasians, and Hawaiians vs. both Asians and American Caucasians; c) The null hypothesis was rejected on female sit-up for American Caucasians vs. Asians, and Pacific Islanders vs. American Caucasians; d) The null hypothesis was rejected on female back extension for Pacific Islanders vs. American Caucasians; and e) The null hypothesis was rejected on female 
bench press for Asians vs. both Pacific Islanders and Hawaiians.

Based upon the data in this study, the following null hypotheses were accepted: 1) No significant differences were found among the female ethnic groups on: a) Sit and reach test; and b) Leg press test.

\section{Discussion}

Analysis of the data resulted in significant differences between the pre and post test for all fitness variables and showed that the EXS 177 course was effective in improving all fitness variables. When compared by ethnic groups, it was found that the American Caucasian students performed better than the Pacific Islanders on the 1.5 mile run, skinfold thickness, sit-up and back extension. The American Caucasian students also performed better than the Hawaiians on the 1.5 mile run and skinfold thickness, and better than the Asians on the situp test and bench press. The Asian female students performed better than the Pacific Islanders and the Hawaiians on the skinfold thickness, and had a higher level of cardiovascular endurance than the Pacific Islanders on the 1.5 mile run. Both the Hawaiian and Pacific Islander female students were significantly stronger than the Asians on the bench press. There were no significant differences for female students as compared by ethnic groups on the sit and reach and leg press.

In general these results suggest that the American Caucasian female students had a higher level of cardiovascular endurance and were leaner than the Pacific Islanders and Hawaiians, and that the Pacific Islander, Hawaiian, and American Caucasian female students were stronger than the Asian female on the bench press. Whether these differences were the result of genetics or socio-cultural factors is unclear. The problem in designing effective evaluative, instructional and motivational strategies may be remedied by the use of ethnicity-specific norms. The data in this study were used to establish norms by decile for each ethnic group on each fitness test.

\section{Recommendation}

It is clear that there are significant differences on several of the fitness variables among the ethnic groups in this study. This presents a dilemma to the instructors and administrators of the EXS 177 Fitness for Life Course. If the differences are only due to genetic factors, it would appear that students in the various ethnic groups should be evaluated on criteria specific to their group. It is known that exercise and dietary habits affect performance on fitness tests. An analysis of the differences in diet and exercise habits among the ethnic groups should be conducted in a future study.

If it is found that the differences in fitness test variables are primarily due to diet and exercise habits, then intervention should be made with Pacific Islanders and Hawaiians to modify their diet and exercise habits and all ethnic groups should be evaluated on a common criterion standard. If it is found that the diet and exercise habits of Pacific Islanders and Hawaiians are not significantly different from American Caucasians, then it must be concluded that genetic factors cause the observed differences. Under this condition, criteria for evaluating fitness parameters specific to each ethnic group should be developed.

\section{References}

American Alliance for Health, Physical Education, Recreation and Dance. (1957). AAHPERD Physical Fitness Test Manual. Reston, VA: AAHPERD.

Bungum, T. J., Jackson, A. W., and Weiller, K. H. (1998). One-mile run performance and body mass index in Asian and Pacific Islander youth: Passing rates for the fitnessgram. Research Quarterly for Exercise and Sport, 69, 89-93.

Craig, P., Halavatau, V., Comino, E., and Caterson, I. (2001). Differences in body composition between Tongans and Australians: Time to rethink the healthy weight ranges? International Journal of Obesity, 25, 1806-1814. 
Deurenberg, P., Yap, M., and van Staveren, W. A. (1998). Body mass index and percent body fat: A meta-analysis among different ethnic groups. International Journal of Obesity, 22, 1164-1171.

Deurenberg, P., Deurenberg-Yap, M., Lin, F. P., and Schmidt, G. (1999). The impact of body build on the relationship between body mass index and percent body fat. International Journal of Obesity, 23, 537-542.

Deurenberg P., Deurenberg-Yap, M, and Schouten, F. J. (2002). Validity of total and segmental impedance measurements for predicting body composition across ethnic population groups. European Journal of Clinical Nutrition, 56, 214-220.

Deurenberg-Yap, M., Schmidt, G., van Staveren, W. A. and Deruenberg, P. (2000). The paradox of low body mass index and high body fat percentage among Chinese, Malays and Indians in Singapore. International Journal of Obesity, 24, 1011-1117.

Fernandez, J. R., Heo, M., Heymsfield, S. B., Pierson, R. N., Xavier Pi-Sunyer, F., Wang, Z. A., Wang, J., Hayes, M., Allison, D. B., and Gallagher, D. (2003). Is percentage body fat differentially related to body mass index in Hispanic Americans, African Americans, and European Americans. American Journal of Clinical Nutrition, 77, 71-75.

Gallagher, D., Heymsfield, S. B., Moonseong, H., Jebb, S. A., Murgatroyd, P. R., and Sakamoto, Y. (2000). Healthy percentage body fat ranges: An approach for developing guidelines based on body mass index. American Journal of Clinical Nutrition, 72, 694-701.

Guirrici, S., Hartriyanti, Y., Hautvast, J., Deurenberg, P. (1999). Differences in the relationship between body fat and body mass index between two different Indonesian ethnic groups: The effect of body build. European Journal of Clinical Nutrition, 53, 468-472.

Looney, M. A., and Plowman, S. A. (1900). Passing rates of American children and youth on the fitnessgram criterion-referenced physical fitness standards. Research Quarterly for Exercise and Sport, 61, 215-223.

Norgan, N. G. (1995). The assessment of the body composition of populations. In P. S. W. Davies (Ed.), Body composition techniques in health and diseases (pp. 195-221). Cambridge: Cambridge University Press.

Pivarnik, J. M., Bray, M. S., Hergenroeder, A. C., Hill, R. B., and Wong, W. W. (1995). Ethnicity affects aerobic fitness in U.S. adolescent girls. Medicine and Science in Sports and Exercise, 27, 16351638.

Rush, E. C., Plank, L. D., Laulu, M. S., Robinson, S. M. (1997). Prediction of percentage body fat from anthropometric measurements: Comparison of New Zealand European and Polynesian young women. American Journal of Clinical Nutrition, 66, 2-7.

Swimburn, B. A., Ley, S. J., Carmichael, H. E., and Plank, L. D. (1999). Body size and composition in Polynesians. International Journal of Obesity, 23, 1178-83.

Thomas, K. T., Keller, C. S., and Holbert, K. E. (1997a). Ethnic and age trends for body composition in women residing in the U. S. Southwest: I - Regional fat. Medicine and Science in Sports and Exercise, 29, 82-89.

Thomas, K. T., Keller, C. S., and Holbert, K. E. (1997b). Ethnic and age trends for body composition in women residing in the U. S. southwest II - Total fat. Medicine and Science in Sports and Exercise, 29, 90-98.

Wagner, D. R., and Heyward, V. H. (2000). Measures of body composition in blacks and whites: A Comparative Review. American Journal of Clinical Nutrition, 71, 1392-1402.

Wang, J., Thornton, J. S., Russell, M., Burastero, S., Heymsfield, S., and Pierson Jr., R. N. (1994). Asians have lower body mass index (BMI) but higher percent body fat than do whites: Comparisons of anthropometric measurements. American Journal of Clinical Nutrition, 60, 23-28.

World Health Organization. (1998). Obesity: Preventing and managing the global epidemic. Report on a WHO consultation. Technical Report Series, No 894. Geneva: Author. 


\author{
Author Information \\ Donna Chun \\ Department of Exercise and Sport Science \\ Brigham Young University - Hawaii \\ 55-220 Kulanui Street \\ Laie, HI 96762 \\ Ph.: 808-293-3353 \\ Fax.: 808-293-3754 \\ E-Mail: chund@byuh.edu \\ Norman Eburne \\ Brigham Young University - Hawaii \\ Joseph Donnelly \\ Montclair State University \\ Norman Kaluhiokalani \\ Joke Kokkonen \\ Jana Whitehead \\ Brigham Young University - Hawaii
}




\section{Appendix A}

Results of Tukey HSD Post-Hoc Tests by Racial/Ethnic Groups

Table 1

Differences When Comparing the 1.5 Mile Test by Ethnic Groups*

\begin{tabular}{|l|l|l|l|l|l|}
\hline \multicolumn{1}{|c|}{ Ethnic Category } & Asian & $\begin{array}{l}\text { American } \\
\text { Caucasian }\end{array}$ & $\begin{array}{l}\text { European } \\
\text { Caucasian }\end{array}$ & Pacific Islander & Hawaiian \\
\hline Asian & X & No & No & Yes (p=.002) & No \\
\hline American Caucasian & ---- & X & No & Yes $(\mathrm{p}=.000)$ & Yes (p=.004) \\
\hline European Caucasian & --- & --- & X & --- & No \\
\hline Pacific Islander & --- & --- & --- & X & No \\
\hline Hawaiian & --- & --- & --- & --- & X \\
\hline
\end{tabular}

Tukey HSD Post-Hoc Test; $\mathrm{F}=11.846, \mathrm{p}=.000$

*Means: Asian = 947.96 ( $=71)$; American Caucasian= $886.66(\mathrm{~N}=131)$; European Caucasian = $906.80(\mathrm{~N}=10)$;

Pacific Islander = $1059.43(\mathrm{~N}=69)$; Hawaiian = $1004.50(\mathrm{~N}=36)$

Table 2

Differences When Comparing Skinfold Thickness by Ethnic Groups*

\begin{tabular}{|l|l|l|l|l|l|}
\hline \multicolumn{1}{|c|}{ Ethnic Group } & Asian & $\begin{array}{l}\text { American } \\
\text { Caucasian }\end{array}$ & $\begin{array}{l}\text { European } \\
\text { Caucasian }\end{array}$ & Pacific Islander & Hawaiian \\
\hline Asian & X & No & No & Yes $(\mathrm{p}=.000)$ & Yes $(\mathrm{p}=.016)$ \\
\hline American Caucasian & --- & X & No & Yes $(\mathrm{p}=.000)$ & Yes $(\mathrm{p}=.041)$ \\
\hline European Caucasian & --- & --- & X & No & No \\
\hline Pacific Islander & --- & --- & --- & X & No \\
\hline Hawaiian & --- & --- & --- & --- & X \\
\hline
\end{tabular}

Tukey HSD Post-Hoc Test; $\mathrm{F}=9.255, \mathrm{p}=.000$

*Means: Asian = $21.09(\mathrm{~N}=69)$; American Caucasian = $21.85(\mathrm{~N}=127)$; European = $24.78(\mathrm{~N}=9)$; Pacific Islander

= $26.91(\mathrm{~N}=66) ;$ Hawaiian $=25.43(\mathrm{~N}=35)$

Table 3

Differences When Comparing the Sit-up Test by Ethnic Groups*

\begin{tabular}{|l|l|l|l|l|l|}
\hline \multicolumn{1}{|c|}{ Ethnic Group } & Asian & \multicolumn{1}{|c|}{$\begin{array}{c}\text { American } \\
\text { Caucasian }\end{array}$} & $\begin{array}{c}\text { European } \\
\text { Caucasian }\end{array}$ & Pacific Islander & Hawaiian \\
\hline Asian & $\mathrm{X}$ & Yes(p=.000) & No & No & No \\
\hline American Caucasian & --- & X & No & Yes(p=.000) & No \\
\hline European Caucasian & --- & --- & X & No & No \\
\hline Pacific Islander & --- & --- & --- & X & No \\
\hline Hawaiian & --- & --- & --- & --- & X \\
\hline
\end{tabular}

Tukey HSD Post-Hoc Test; $\mathrm{F}=7.993, \mathrm{p}=.000$

*Means: Asian = $30.21(\mathrm{~N}=68)$; American Caucasian = $37.39(\mathrm{~N}=127)$; European Caucasian = $33.00(\mathrm{~N}=9)$; Pacific

Islander = $29.93(\mathrm{~N}=68)$; Hawaiian = $33.00(\mathrm{~N}=36)$ 
Table 4

Differences When Comparing the Back Extension Test by Ethnic Groups*

\begin{tabular}{|l|l|l|l|l|l|}
\hline \multicolumn{1}{|c|}{ Ethnic Group } & Asian & $\begin{array}{c}\text { American } \\
\text { Caucasian }\end{array}$ & $\begin{array}{l}\text { European } \\
\text { Caucasian }\end{array}$ & Pacific Islander & Hawaiian \\
\hline Asian & X & No & No & No & No \\
\hline American Caucasian & --- & X & No & Yes(p =.001) & No \\
\hline European Caucasian & --- & --- & X & No & No \\
\hline Pacific Islander & --- & --- & --- & X & No \\
\hline Hawaiian & --- & --- & --- & --- & X \\
\hline
\end{tabular}

Tukey HSD Post-Hoc Test; $\mathrm{F}=4.021, \mathrm{p}=.003$

*Means: Asian = $53.00(\mathrm{~N}=68)$; American = $54.83(\mathrm{~N}=128)$; European = $52.30(\mathrm{~N}=10)$; Pacific Islander $=46.88$

$(\mathrm{N}=68) ;$ Hawaiian $=52.00(\mathrm{~N}=35)$

Table 5

Differences When Comparing the Bench Press Test by Ethnic Groups*

\begin{tabular}{|l|l|l|l|l|l|}
\hline \multicolumn{1}{|c|}{ Ethnic Group } & Asian & \multicolumn{1}{|c|}{$\begin{array}{c}\text { American } \\
\text { Caucasian }\end{array}$} & $\begin{array}{c}\text { European } \\
\text { Caucasian }\end{array}$ & Pacific Islander & Hawaiian \\
\hline Asian & X & Yes $(\mathrm{p}=.004)$ & No & Yes $(\mathrm{p}=.000)$ & Yes $(\mathrm{p}=.001)$ \\
\hline American Caucasian & ---- & X & No & No & No \\
\hline European Caucasian & --- & --- & X & No & No \\
\hline Pacific Islander & --- & --- & --- & X & No \\
\hline Hawaiian & --- & --- & --- & --- & X \\
\hline
\end{tabular}

Tukey HSD Post-Hoc Test; F $=6.116, \mathrm{p}=.000$

*Means: Asian = $64.26(\mathrm{~N}=61)$; American = $76.87(\mathrm{~N}=119)$; European = $71.00(\mathrm{~N}=10)$; Pacific Islander $=82.02(\mathrm{~N}=$ $61)$; Hawaiian $=82.79(\mathrm{~N}=34)$ 


\section{Appendix B}

Percentile Scores for Fitness Tests by Race/Ethnicity

Table 1

Percentile Scores for Asian Female Fitness Components

\begin{tabular}{|c|c|c|c|c|c|c|c|}
\hline Percentile & 1.5 Mile & Skinfold & Sit/Reach & Sit-up & Back Extension & Bench Press & Leg Press \\
\hline 90 & 711.20 & 15.00 & 20.00 & 52.10 & 85.00 & 98.00 & 214.00 \\
\hline 80 & 756.40 & 16.00 & 19.00 & 50.20 & 83.00 & 85.00 & 177.60 \\
\hline 70 & 790.60 & 17.00 & 18.00 & 44.30 & 78.60 & 75.00 & 162.20 \\
\hline 60 & 812.40 & 18.00 & 17.00 & 41.40 & 75.00 & 75.00 & 144.00 \\
\hline 50 & 836.00 & 19.00 & 16.00 & 39.00 & 70.50 & 65.00 & 130.00 \\
\hline 40 & 870.00 & 20.00 & 16.00 & 35.00 & 66.20 & 65.00 & 111.00 \\
\hline 30 & 902.00 & 21.00 & 15.00 & 33.00 & 61.40 & 60.00 & 100.00 \\
\hline 20 & 963.00 & 24.00 & 14.00 & 30.80 & 58.00 & 60.00 & 100.00 \\
\hline 10 & 1059.60 & 29.00 & 13.00 & 26.90 & 52.90 & 55.00 & 89.00 \\
\hline
\end{tabular}

Table 2

Percentile Scores for American Caucasian Female Fitness Components

\begin{tabular}{|c|c|c|c|c|c|c|c|}
\hline Percentile & 1.5 Mile & Skinfold & Sit/Reach & Sit-up & Back Extension & Bench Press & Leg Press \\
\hline 90 & 639.60 & 15.00 & 21.00 & 57.00 & 87.10 & 105.00 & 240.00 \\
\hline 80 & 681.40 & 17.00 & 20.00 & 51.00 & 79.00 & 100.00 & 206.40 \\
\hline 70 & 706.60 & 18.00 & 19.00 & 48.00 & 75.00 & 90.00 & 176.00 \\
\hline 60 & 727.80 & 19.00 & 19.00 & 45.00 & 73.00 & 85.00 & 163.00 \\
\hline 50 & 770.00 & 21.00 & 18.00 & 43.00 & 70.00 & 80.00 & 144.00 \\
\hline 40 & 820.60 & 22.00 & 17.00 & 40.00 & 68.00 & 75.00 & 132.00 \\
\hline 30 & 864.80 & 25.00 & 17.00 & 36.00 & 64.00 & 75.00 & 120.00 \\
\hline 20 & 912.20 & 27.00 & 15.00 & 33.00 & 59.80 & 70.00 & 110.00 \\
\hline 10 & 1018.20 & 30.20 & 14.00 & 29.80 & 51.00 & 65.00 & 100.00 \\
\hline
\end{tabular}

Table 3

Percentile Scores for European Female Fitness Components

\begin{tabular}{|c|l|c|c|c|c|c|c|}
\hline Percentile & 1.5 Mile & Skinfold & Sit/Reach & Sit-up & Back Extension & Bench Press & Leg Press \\
\hline 90 & 775.50 & 16.00 & 21.80 & 51.00 & 84.10 & 117.50 & 268.00 \\
\hline 80 & 800.60 & 20.00 & 19.80 & 45.00 & 75.80 & 94.00 & 230.00 \\
\hline 70 & 817.00 & 21.00 & 18.70 & 43.00 & 74.70 & 87.00 & 181.00 \\
\hline 60 & 838.60 & 23.00 & 18.00 & 43.00 & 73.20 & 78.00 & 160.00 \\
\hline 50 & 850.50 & 26.00 & 17.50 & 42.00 & 71.00 & 75.00 & 152.00 \\
\hline 40 & 851.60 & 27.00 & 17.00 & 41.00 & 68.20 & 72.00 & 135.60 \\
\hline 30 & 896.10 & 29.00 & 16.30 & 40.00 & 67.00 & 70.00 & 116.00 \\
\hline 20 & 960.60 & 31.00 & 16.00 & 34.00 & 67.00 & 66.00 & 110.00 \\
\hline 10 & 1190.70 & 32.00 & 12.40 & 30.00 & 60.70 & 65.00 & 101.00 \\
\hline
\end{tabular}


Table 4

Percentile Scores for Pacific Islander Female Fitness Components

\begin{tabular}{|c|c|c|c|c|c|c|c|}
\hline Percentile & 1.5 Mile & Skinfold & Sit/Reach & Sit-up & Back Extension & Bench Press & Leg Press \\
\hline 90 & 745.00 & 17.00 & 20.00 & 50.10 & 82.10 & 133.00 & 240.00 \\
\hline 80 & 818.00 & 19.00 & 18.00 & 46.20 & 76.00 & 112.20 & 208.00 \\
\hline 70 & 890.00 & 21.00 & 17.00 & 43.00 & 70.90 & 105.00 & 190.00 \\
\hline 60 & 945.00 & 22.00 & 17.00 & 40.40 & 68.00 & 95.00 & 175.60 \\
\hline 50 & 977.00 & 24.50 & 17.00 & 38.00 & 64.00 & 85.00 & 160.00 \\
\hline 40 & 1013.00 & 27.00 & 16.00 & 36.00 & 60.00 & 84.00 & 140.00 \\
\hline 30 & 1042.00 & 28.00 & 15.00 & 35.00 & 58.00 & 75.00 & 120.00 \\
\hline 20 & 1111.00 & 31.00 & 15.00 & 31.00 & 55.00 & 70.00 & 120.00 \\
\hline 10 & 1185.00 & 37.30 & 13.90 & 28.60 & 47.70 & 65.00 & 110.00 \\
\hline
\end{tabular}

Table 5

Percentile Scores for Hawaiian Female Fitness Components

\begin{tabular}{|c|c|c|c|c|c|c|c|}
\hline Percentile & 1.5 Mile & Skinfold & Sit/Reach & Sit-up & Back Extension & Bench Press & Leg Press \\
\hline 90 & 739.40 & 17.00 & 19.00 & 53.00 & 86.20 & 127.50 & 240.00 \\
\hline 80 & 778.00 & 18.00 & 18.00 & 50.00 & 78.80 & 110.00 & 200.80 \\
\hline 70 & 824.60 & 19.80 & 18.00 & 49.90 & 73.20 & 100.00 & 175.90 \\
\hline 60 & 873.00 & 22.00 & 17.00 & 42.60 & 71.20 & 90.00 & 161.00 \\
\hline 50 & 904.00 & 24.00 & 16.00 & 39.50 & 65.00 & 85.00 & 150.00 \\
\hline 40 & 960.00 & 25.00 & 15.00 & 36.60 & 60.40 & 80.00 & 144.00 \\
\hline 30 & 974.90 & 27.20 & 15.00 & 34.00 & 59.80 & 75.00 & 140.00 \\
\hline 20 & 1022.00 & 29.60 & 15.00 & 26.40 & 53.00 & 70.00 & 124.00 \\
\hline 10 & 1074.00 & 33.00 & 13.00 & 22.00 & 50.00 & 62.50 & 97.00 \\
\hline
\end{tabular}

